\title{
Erratum
}

\section{The Female Knee: Anatomic Variations and the Female-specific Total Knee Design}

\author{
Alan C. Merchant MD, Elizabeth A. Arendt MD, Scott F. Dye MD, \\ Michael Fredericson MD, Ronald P. Grelsamer MD, Wayne B. Leadbetter MD, \\ William R. Post MD, Robert A. Teitge MD
}

Published online: 3 December 2008

(C) The Association of Bone and Joint Surgeons 2008

\section{Erratum to: Clin Orthop Relat Res DOI 10.1007/s11999-008-0536-5}

Shortly after our article "The female knee: anatomic variations and the female-specific total knee design" went to press [3], we learned that one of our references [1] had changed significantly.

In September 2007, after reading an article about the female knee and its anatomic variations [2] in The Journal of the American Academy of Orthopaedic Surgeons (JAAOS), we submitted a scientifically-based response to that journal to be published as a Commentary. The Editor-in-Chief stated that the Commentary could be shortened to no more than 500 words as a Letter-to-the-Editor, or he would welcome the submission of a formal manuscript. Therefore, we

The online version of the original article can be found under doi: 10.1007/s11999-008-0536-5.

Electronic supplementary material The online version of this article (doi:10.1007/s11999-008-0650-4) contains supplementary material, which is available to authorized users.

\section{A. C. Merchant $(\bowtie)$}

Department of Orthopaedic Surgery, Stanford University School of Medicine, 124 Marvin Avenue, Los Altos, CA 94022, USA e-mail: kneemd@sbcglobal.net

\section{E. A. Arendt}

Department of Orthopaedic Surgery, University of Minnesota,

Minneapolis, MN, USA

\section{S. F. Dye}

Department of Orthopaedic Surgery, University of California

San Francisco, San Francisco, CA, USA

\section{Fredericson}

Department of Orthopaedic Surgery, Stanford University School of Medicine, Stanford, CA, USA submitted a formal manuscript to the JAAOS on October 23, 2007.

On January 28, 2008, after receiving no response for 3 months, we contacted the JAAOS for a status report. On February 5, 2008 the Editor-in-Chief responded by saying that, in the interim, the AAOS Technical Committee had addressed the issue of gender-specific total knee arthroplasties in the February 2008 issue. Therefore, the JAAOS editors and other AAOS leadership had decided not to publish any additional communication related to the issue of gender-specific total knee replacements. After receiving our February 2008 issue of the JAAOS, and deciding to submit a manuscript to Clinical Orthopedics and Related Research, we used that Technical Overview article (Supplementary Appendix 1, page 63) as Reference 2 , but noted that it had been published anonymously.

Recently we reviewed that Technical Overview article again on the JAAOS web site archive. A list of authors had been added to the archived Technical Overview article (Supplementary Appendix 2, page 63). We found no notification in the archived article that it originally had

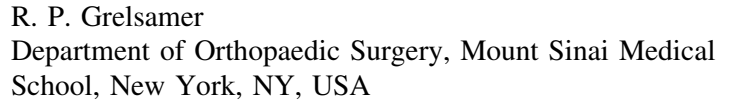

W. B. Leadbetter

Center for Joint Preservation and Replacement, Rubin Institute for Advanced Orthopaedics, Sinai Hospital, Baltimore, MD, USA

W. R. Post

Mountaineer Orthopedic Specialists, LLC, Morgantown, WV, USA

R. A. Teitge

Wayne State University, Warren, MI, USA 
been published anonymously and authors had been added at a later date. We searched subsequent issues of the JAAOS from March through the current issue (November 2008), and found no Erratum or Commentary explaining this change. A majority of the orthopaedic surgeon authors who had been added to the article documented conflicts of interest related to the subject.

We submit this erratum to show that our reference to the anonymous Technology Overview article (Supplementary Appendix 1) in JAAOS was accurate, because that article, as originally published, no longer exists on the JAAOS web site archive. It only can be found as Supplementary Appendix 1 in this Erratum.

\section{References}

1. Anonymous. Gender-specific knee replacements: a technology overview. J Am Acad Orthop Surg. 2008;16:63-67.

2. Conley S, Rosenberg A, Crowninshield R. The female knee: anatomic variations. J Am Acad Orthop Surg. 2007;15(suppl 1): S31-S36.

3. Merchant AC, Arendt EA, Dye SF, Fredericson M, Grelsamer RP, Leadbetter WB, Post WR, Teitge RA. The female knee: anatomic variations and the female-specific total knee design. Clin Orthop Relat Res. 2008;466:3059-3065. 